\title{
Study on the Biological Safety of Arginine-modified Hydroxyapatite Nanoparticles
}

\author{
Min Yang ${ }^{1}$, Junjie Sun ${ }^{1}$, Yanzhong Zhao ${ }^{1,2,{ }^{*}}$,Zewen Song ${ }^{1}$, Haibin Zhang ${ }^{1}$, Shaihong Zhu ${ }^{1,2}$ \\ ${ }^{1}$ The Third Xiangya Hospital, Central South University, Changsha 410013, China \\ ${ }^{2}$ Research Center for Medical Material and Instruments, Central South University, Changsha 410013, China \\ Email: yanzhongzhao@163.com
}

\begin{abstract}
This study was to investigate the biological safety of arginine-modified hydroxyapatite nanoparticles (HAP/Arg) as a gene carrier for gene therapy. Experiments were conducted on normal human vascular endothelial cells (HAEC) and human tumor cells (Hela cells) to study the biological safety of HAP/Arg at subcellular level, cellular level, and overall level of animal. Cell proliferation, structural integrity of cell membrane, acute toxicity of HAP/Arg and animal reproductive toxicity of HAP/Arg were all examined. The results showed that HAP/Arg of various doses did not significantly affect normal growth and cell membrane structure of HAEC cells and Hela cells, when these cells were treated for different duration. Acute toxicity experiments and general reproductive toxicity experiments on animals also revealed no significant difference between each HAP/Arg dose group and control group. These results could lay the foundation for the construction of a novel and safe HAP gene delivery system.
\end{abstract}

Keywords: Hydroxyapatite, gene carrier, arginine-modification, biological safety.

\section{Introduction}

Hydroxyapatite (HA) is the most common bioactive material which has been applied widely in bio-medical field. In recent years, with the development of nanotechnology, many studies have found that hydroxyapatite nanoparticles (HAP) are deemed to be ideal gene carriers because of its good biological stability, easy preparation and modification [1-3]. In our previous studies, HAP can transfer a therapeutic gene and a reporter gene in vitro and in vivo [4-6]. Simultaneously, arginine-modified hydroxyapatite nanoparticles (HAP/Arg) could enhance gene delivery efficiency [7,8]. However, great attention has been attached to the biological safety of nano materials since the start of this century [9-13]. HA has been widely used in clinic as a good artificial bone material and tissue material, and its safety has reached relevant standards of ISO10993[14], but compared with conventional materials, HAP has different physical and chemical properties and its biological effects can be influenced by its size, chemical composition, surface structure, morphology and aggregation state $[15,16]$. Some studies summarized the biological evaluation, toxicity in vivo and cytotoxicity of HAP, and concluded that the instability of chemical structure of HAP had little influence on its biological safety [17]. But some studies also revealed that HAP could migrate in vivo and may lead to local inflammation [18]. These phenomena have to be considered. Therefore, it's essential to evaluate the biological safety of HAP/Arg as a gene carrier for clinical applications. Although a variety of cell line models were used to study the mechanism of toxicity in vitro, vascular endothelial cells as a cell line model to study the toxicity of nanoparticles could only be found in a few reports [19]. And study of the toxic effect of HAP/Arg on vascular endothelial cells will be helpful for further study on the mechanism of HAP/Arg.

In this study, HAP/Arg as a drug carrier for gene therapy was synthesized and relevant standards of ISO7406 technical report were followed. Normal human vascular endothelial cells (HAEC) and human tumor cells (Hela cells) were chosen as in vitro cell models. This study investigated the biological safety of $\mathrm{HAP} /$ Arg at subcellular level, cellular level, and overall level of animal. The feasibility of nano-hydroxyapatite as a gene drug carrier was evaluated by the MTT 
(3-(4,5-dimethylthiazol-2-yl)-2,5-diphenyltetrazolium bromide) assay, LDH (Lactate dehydrogenase) methods, animal acute toxicity experiments and general reproductive toxicity experiments.

\section{Materials and Methods}

\subsection{Materials}

In this study, the materials were used as following: HAP/Arg nanoparticles (State Key Laboratory of Powder Metallurgy, Central South University), Kunming mice (Department of Animal Experiment, Central South University, Class: SPF class, Animal license: No: SYXK., (Hunan) 2010-0001), human vascular endothelial cells (HAEC) and human tumor cells (Hela cells) (Saizy (Shanghai) Biological Engineering CO., LTD), limulus reagent (Xiamen Limulus Reagent Trial Factory CO.,LTD), MTT, dimethyl sulfoxide (DMSO) and LDH reagent (Sigma company).

\subsection{The Endotoxin Test of Nanoparticles Suspension}

Glassware was washed by chromic acid, tap water and distilled water, then it was wrapped in foil, placed in the oven, and baked at $250^{\circ} \mathrm{C}$ for more than $60 \mathrm{~min}$. The sensitivity of limulus reagent met the requirements according to check detection. HAP/Arg samples were numbered and were then diluted by adding $0.1 \mathrm{ml}$ endotoxin dilution special water into each tube. A tube of bacterial endotoxin national standard goods was dissolved by bacterial endotoxin dilution special water, then tube was covered with sealing film and mixed on a vortex device for $20 \mathrm{~min}$. Next, it was diluted to $2.0 \lambda 、 1.0 \lambda 、 0.5 \lambda 、 0.25 \lambda$ (four concentrations of bacterial endotoxin standard solution). According to the sample tube (0.1 ml of sample solution $+0.1 \mathrm{ml}$ of reagent), sample of positive $(0.1 \mathrm{ml}$ of sample solution $+0.1 \mathrm{ml}$ of $4 \lambda$ of endotoxin diluent, stirred $30 \mathrm{~s}, 0.1 \mathrm{~mL}$ of intermixture $+0.1 \mathrm{ml}$ of reagent), positive tube $(0.1 \mathrm{ml}$ of $2 \lambda$ of endotoxin diluent $+0.1 \mathrm{ml}$ of reagent $)$, negative tube $(0.1 \mathrm{ml}$ of endotoxin dilution special water $+0.1 \mathrm{ml}$ of reagent), the sample and reagent were added to six tubes with $0.1 \mathrm{ml}$ of limulus reagent solution, then tubes were shaken with operating panel on the desktop for $30 \mathrm{~s}$ and were sealed with sealing film. Subsequently, all experimental tubes, together with the test tube rack (which must maintain the level of state), were putted into thermostat which could kept for $60 \pm 2$ min under the condition of $37 \pm 1^{\circ} \mathrm{C}$. Finally, experimental reaction tubes were took out and inverted 180 degrees for observation. Samples passing the above test would be used for following studies.

\subsection{The Test of Cell Proliferation by MTT Assay}

The human normal vascular endothelial cells (HAEC) and human tumor cells (Hela cells) were inoculated on 96 hole plate $\left(150 \mu \mathrm{L}\right.$ per hole) with $2 \times 10^{4} / \mathrm{ml}$ density, and were cultured to exponential growth phase (24 h). Each group has 3 holes, and a blank control group was also set. Meanwhile, culture solution containing $0.1 \%$ of serum was preserved for up to $3 \mathrm{~h}$ at $4{ }^{\circ} \mathrm{C}$ refrigerator. In this way, the majority of cells would enter into the S phase. Subsequently, $50 \mu \mathrm{L} \mathrm{HAP} / \mathrm{Arg}$ suspension of different concentration $(0 \mu \mathrm{g} / \mathrm{ml}$, $25 \mu \mathrm{g} / \mathrm{ml}, 50 \mu \mathrm{g} / \mathrm{ml}$ and $200 \mu \mathrm{g} / \mathrm{ml}$ ) was added and mixed. After culturing for $4 \mathrm{~h}, 24 \mathrm{~h}, 48 \mathrm{~h}$, or $72 \mathrm{~h}, 20 \mu \mathrm{L}$ $5 \mathrm{mg} / \mathrm{ml}$ MTT preservation solution was added into each hole. The panel was shaken and incubated for another $4 \mathrm{~h}$. The liquid supernatant was then absorbed. $100 \mu \mathrm{L}$ of ethanol and dimethyl sulfoxide (DMSO) mixture (1:1) were added into each hole, and were shaken on oscillation table at a low speed for 10 min to dissolve the crystal fully. The OD absorbance at different times was measured by enzyme labeled immunoassay instrument at $490 \mathrm{~nm}$ wave. At the same time, zero pore (medium, MTT and DMSO) and control pore (cells, nanoparticle dissolution medium of the same concentration, medium, MTT and DMSO) were set; duplicate pores were also set for each group. Finally, according to the mean of cell survival rates of the 5 holes in each group (cell survival rate $=(\mathrm{OD}$ value of experimental-OD value of group blank) / $(\mathrm{OD}$ value of control group-OD value of blank group) $\times 100 \%$ ), cytotoxicity of HAP $/$ Arg was deduced. 


\subsection{The Test of Structural Integrity of Cell Membrane by LDH Method}

Logarithmic growth phase cells were vaccinated, hatched and synchronized according to the method of 1.3. Subsequently, HAP/Arg suspension was added to make final concentration to $0 \mu \mathrm{g} / \mathrm{ml}, 25 \mu \mathrm{g} / \mathrm{ml}, 50$ $\mu \mathrm{g} / \mathrm{ml}$ and $200 \mu \mathrm{g} / \mathrm{ml}$. Cells were incubated for $4 \mathrm{~h}, 24 \mathrm{~h}, 48 \mathrm{~h}$ and $72 \mathrm{~h}$ with HAP/Arg suspension of different concentration. Meanwhile, equal amount of culture fluid was added in the control group. Each concentration group and control group were set up five parallel holes. Finally, LDH kit method would be used to test extracellular LDH level.

\subsection{The Acute Toxicity of HAP/Arg}

80 healthy Kunming mice were used in this study. These mice fasted with water only for $16 \mathrm{~h}$ and they were separated according to their genders. All mice were randomly divided into four groups: low dose group $(10 \mu \mathrm{g} / \mathrm{ml} / 20 \mathrm{~g}$ of weight), middle dose group $(100 \mu \mathrm{g} / \mathrm{ml} / 20 \mathrm{~g}$ of weight), high dose group $(500 \mathrm{\mu g} / \mathrm{ml} / 20 \mathrm{~g}$ of weight) and control group (equal volume of normal saline). Each group has 20 mice, half male and half female. After injecting different doses of HAP/Arg suspension through caudal vein in experimental groups and injecting equal volume of normal saline in blank control group, general activity behavior, weight, feed intake, hair, stool, urine and breath of mice were observed daily and death was counted. On the observation of death of mice, the animals were dissected immediately and the main organs were taken out and examined by tissue slice, light microscopy and electron microscopy. To detect the serum biochemical indexes of animals, 8 mice were randomly selected from each group one day after drug withdrawal, and then their eyeballs were removed for blood after being fasted for $12 \mathrm{~h}$. Two mice were randomly selected from each group and were killed by cervical dislocation. Heart, liver, spleen, lung, kidney and muscle were removed for paraffin embedded sections. Pathological characteristics were observed by inverted fluorescence microscope. Finally, the remaining animals were executed at the end of the experiment (7 days).

\subsection{The Animal Reproductive Toxicity of HAP/Arg}

According to the results of animal acute toxicity experiment of HAP/Arg, the male and female mice were randomly divided into three treatment groups and a control group, namely low dose group $(0.09 \mathrm{mg} /$ $\mathrm{kg} \cdot \mathrm{d})$, middle dose group $(4.5 \mathrm{mg} / \mathrm{kg} \cdot \mathrm{d})$, high dose group $(225 \mathrm{mg} / \mathrm{kg} \cdot \mathrm{d})$ and control group. Each group had 20 male and 15 female mice. After being fasted with water only for 16 hours, each mouse in experimental groups was injected continuously the corresponding dose of HAP/Arg suspension through caudal vein for 9 weeks and 12 weeks (twice a week). Subsequently, male mice and female mice at a ratio of 1:1 were fed in the same cage for 5 days. During this period, the male mice were injected continuously to 11th weeks (twice a week), while the female mice were injected continuously to 15th days of pregnancy (twice a week). At the same time, equal volume of normal saline was injected through caudal vein into mice in blank control group. Reproductive toxicity was then determined according to the preclinical safety evaluation criteria of new drug ${ }^{[20]}$. The average number of weight, corpora luteum, implantation, live births of male and female mice, and weight of fetal mice and so on were compared by F-test, and the rate of mating and pregnancy were compared by $x^{2}$-test.

Table 1. Administration program of HAP/Arg suspension in little white mice.

\begin{tabular}{llllc}
\hline Groups & $\begin{array}{c}\text { Numbers } \\
(\text { 우 / } \mathbf{f})\end{array}$ & $\begin{array}{c}\text { Doses } \\
(\mathbf{m g} / \mathbf{k g})\end{array}$ & Route of medication & Times of administration ( 우 / 占) \\
\hline Control group & $20 / 15$ & 0.00 & tail vein injection & $2 / 4$ \\
Low dose group & $20 / 15$ & 0.09 & tail vein injection & $2 / 4$ \\
Middle dose group & $20 / 15$ & 4.50 & tail vein injection & $2 / 4$ \\
High dose group & $20 / 15$ & 225 & tail vein injection & $2 / 4$ \\
\hline
\end{tabular}




\subsection{Statistical Analysis}

Data were presented as the mean \pm standard deviation. A one-way analysis of variance (ANOVA) (SPSS13.0) test was performed to determine significant differences among treatment groups.

\section{$3 \quad$ Results and Discussion}

\subsection{The Detection of Endotoxin of HAP/Arg}

In order to exclude interference factors of endotoxin in HAP/Arg samples and ensure the reliability of research results, massive endotoxin of the nanoparticles samples must be removed to avoid the effect of endotoxin on the next step of experimental animals. According to the regulations of Chinese biological products (2000 year edition), the preparation process of HAP/Arg was investigated by sterility test and endotoxin test in this experiment. The results of the reaction tube of test samples showed negative, so these samples were considered to meet the Pharmacopoeia standards. Therefore, the HAP/Arg samples could be used for the next step of biological safety research.

\subsection{The Effect of HAP/Arg on Cell Proliferation}

Fig.1 showed the OD values of HAEC and Hela tumor cells in HAP/Arg of different concentration and under different reaction time. The cell viability of each experimental group was not significantly different from that of the control group at all time periods and in HAP/Arg of different concentration. This result illustrated that the dose group had no significant effect on the normal growth of the selected two kinds of cells at different reaction time. From the point of the effect on cell proliferation, the cytotoxicity of HAP nanoparticles modified by arginine was evaluated in vitro by MTT Assay. Meanwhile, according to the principle that the number of survival cells was proportional to absorbance, OD value of HAEC and Hela tumor cells were detected when they were cultured in HAP/Arg of different concentration and for different reaction time.

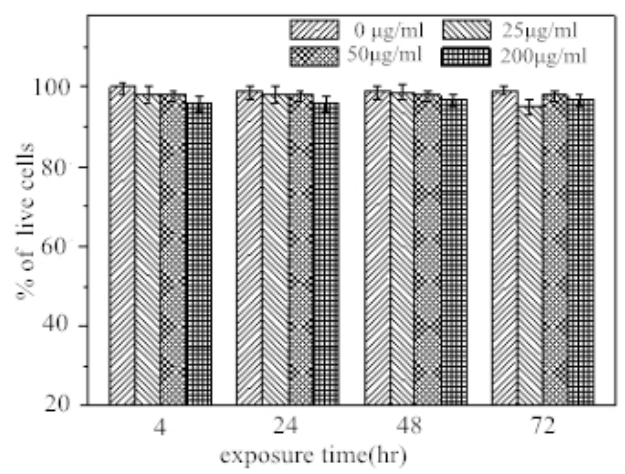

(a)

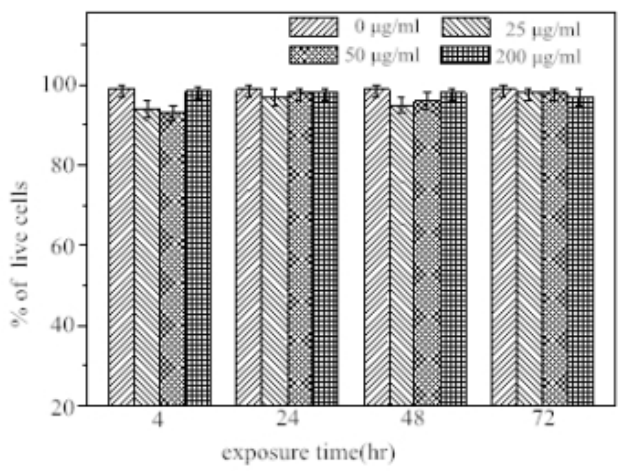

(b)

Figure 1. Cell viability assay. Varying concentrations and exposure time of HAP/Arg showed no effects on (a) Hela cell viability and (b) HAEC cell viability. Results were reported as mean \pm standard deviation. There is no statistically significant difference between test groups and control groups, $\mathrm{P}>0.05$.

\subsection{The Effect of HAP/Arg on the Structural Integrity of Cell Membranes}

Table 2 and table 3 showed the effect of HAP/Arg of different concentrations on LDH (U/L) activity of Hela tumor cells and human aortic endothelial cells at the time of $4 \mathrm{~h}$ to $72 \mathrm{~h}$. When cells were cultured for the same time period, the LDH activity of each experimental group was not statistically different from the control group. However, with the extension of time, the amount of LDH in each experimental group 
increased significantly, indicating that HAP/Arg had little effect on the cell membrane. Under normal circumstances, LDH existed in the cytoplasm; however, it would leak out of cell when the cell membrane was damaged. The increase or decrease in the amount of LDH would affect the normal life activities of body. Consequently, the amount of LDH detected in a cell culture fluid could reflect indirectly the damage degree of the integrity of cell membrane.

Table 2. Effect of HAP/Arg on LDH concentration (U/L) of HeLa cells.

\begin{tabular}{lccccc}
\hline \multirow{2}{*}{ Groups } & HAP/Arg & \multicolumn{4}{c}{ LDH concentration (U/L) } \\
\cline { 3 - 6 } & Concentration $(\boldsymbol{\mu} \mathbf{g} / \mathbf{m l})$ & $\mathbf{4} \mathbf{~ h}$ & $\mathbf{2 4} \mathbf{~ h}$ & $\mathbf{4 8} \mathbf{~ h}$ & $\mathbf{7 2} \mathbf{~ h}$ \\
\hline Control group & 0 & $23.67 \pm 0.29$ & $50.39 \pm 0.98$ & $62.71 \pm 1.21$ & $73.68 \pm 1.53$ \\
Low dose group & 25 & $24.09 \pm 1.53$ & $51.60 \pm 0.44$ & $62.67 \pm 0.50$ & $74.17 \pm 3.01$ \\
Middle dose group & 50 & $25.27 \pm 0.18$ & $52.62 \pm 0.31$ & $64.79 \pm 2.51$ & $73.42 \pm 2.18$ \\
High dose group & 200 & $24.98 \pm 0.35$ & $53.07 \pm 0.68$ & $64.09 \pm 2.11$ & $73.97 \pm 2.03$ \\
\hline
\end{tabular}

Table 3. Effect of HAP/Arg on LDH concentration (U/L) of HAECs cells.

\begin{tabular}{lccccc}
\hline \multirow{2}{*}{ Groups } & HAP/Arg & \multicolumn{4}{c}{$\mathbf{L D H}$ concentration $(\mathbf{U} / \mathbf{L})$} \\
\cline { 3 - 6 } & Concentration $(\boldsymbol{\mu} \mathbf{g} / \mathbf{m l})$ & $\mathbf{4} \mathbf{~ h}$ & $\mathbf{2 4} \mathbf{~ h}$ & $\mathbf{4 8} \mathbf{~ h}$ & $\mathbf{7 2} \mathbf{~ h}$ \\
\hline Control group & 0 & $32.17 \pm 1.37$ & $59.07 \pm 0.55$ & $67.29 \pm 1.33$ & $77.68 \pm 3.08$ \\
Low dose group & 25 & $33.64 \pm 0.48$ & $58.79 \pm 0.84$ & $68.07 \pm 0.19$ & $78.14 \pm 2.33$ \\
Middle dose group & 50 & $32.39 \pm 2.59$ & $58.92 \pm 0.56$ & $67.28 \pm 1.41$ & $79.01 \pm 1.98$ \\
High dose group & 200 & $35.31 \pm 1.08$ & $59.17 \pm 1.78$ & $69.61 \pm 2.88$ & $79.37 \pm 2.14$ \\
\hline
\end{tabular}

\subsection{Acute Toxicity of HAP/Arg}

\subsubsection{The Changes in Behavior and Body Weight of Mice}

Fig. 2 showed the change of weight of mice in each group at 7 days. Weight and the weight gain of Kunming mice of each experimental group were not statistically different from the control group within 7 days $(\mathrm{P}>0.05)$. 7 days after tail vein injection, no obvious abnormalities were observed in the activities, hair color, stool, urine, and breathe of Kunming mice of all experimental groups and the control group. Besides, no significant relationship was found between feed intake of Kunming mice and the effect of nanoparticles.

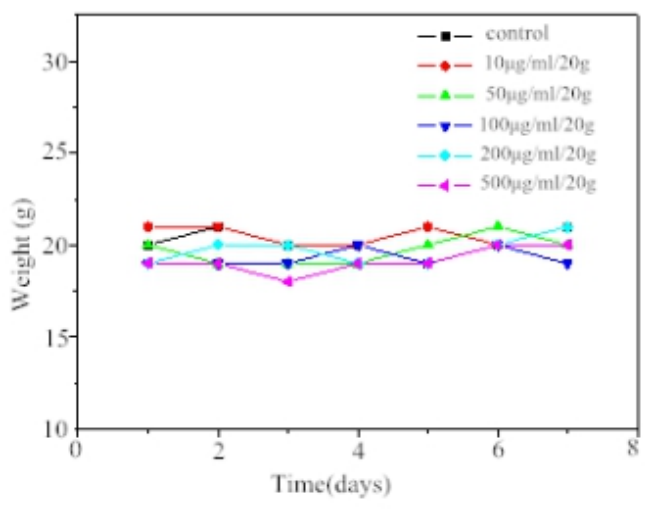

Figure 2. Change trend of body weight of mice within 7 days.

\subsubsection{The Death or Toxicity Reaction of HAP/Arg to Kunming Mice}

Table 4 showed the results of acute toxicity test of mice after HAP/Arg suspension of different doses were injected through tail vein. No death or obvious abnormality was observed in all groups during the experimental period, suggesting that HAP/Arg prepared by hydrothermal synthesis method had no acute 
toxicity on mice. However, the question that whether HAP/Arg had chronic toxicity or reproductive toxicity required further studies.

Table 4. Acute toxicity test in little white mice after injection of HAP/Arg suspension.

\begin{tabular}{llllll}
\hline Groups & $\begin{array}{l}\text { Number } \\
\text { of mice }\end{array}$ & $\begin{array}{l}\text { Doses } \\
(\mathbf{m g} / \mathbf{k g})\end{array}$ & $\begin{array}{l}\text { Route of } \\
\text { medication }\end{array}$ & toxicity test & $\begin{array}{l}\text { Number } \\
\text { of deaths }\end{array}$ \\
\hline Control group & 20 & 225.0 & tail vein injection & No obvious abnormality & 0 \\
Low dose group & 20 & 56.3 & tail vein injection & No obvious abnormality & 0 \\
Middle dose group & 20 & 5.0 & tail vein injection & No obvious abnormality & 0 \\
High dose group & 20 & 0.4 & tail vein injection & No obvious abnormality & 0 \\
\hline
\end{tabular}

3.4.3 The Effect of HAP/Arg on Five Kinds of Serum Biochemical Indexes of Kunming Mice Fig.3 showed the results of biochemical indexes of mice after HAP/Arg suspension of different doses were injected through tail vein. As was shown in Fig 3, the serum alanine amino transfer enzyme (ALT) of mice in the high dose group was obviously different from the control group $(\mathrm{P}<0.05)$, but there was no significant difference between middle dose group or low dose group when compared with normal saline control group $(\mathrm{P}>0.05)$. The results illustrated that high dose group of HAP/Arg could damage liver to a certain degree, and this damage may be associated with the transportation of a large number of particles at 100 200nm to the liver cells by macrophages of the reticular endothelial system (RES) ${ }^{[21]}$. There was no significant difference between other dose groups and control group in such serum biochemical indexes as AST, TP, BUN and CREA. This suggested that HAP/Arg in each dose group were less damage to kidney. This result was consistent with the experimental results did by Liu et al. who analyzed toxic reaction by injecting HAP solution of different doses in rabbits in vivo ${ }^{[22]}$. They found that HAP solution had less effect on the electrolyte and enzyme of animal and no cumulative toxicity was observed. LDH, CPK, GOP, BUN, ALP and so on showed only a transient change and then returned to normal.

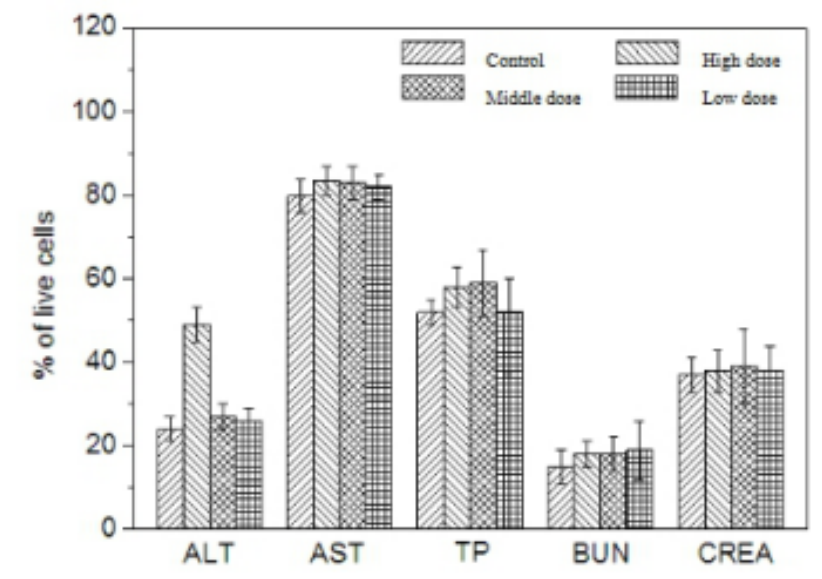

Figure 3. Biochemical assay of serum.

\subsubsection{The Pathological Observation of HAP/Arg on Various Organs of Kunming Mice}

Fig.4 showed the pathological sections of organs of mice. As was shown in Fig.4, no inflammation or damage to the cell structure was observed in tissues in each experimental group and control group. 

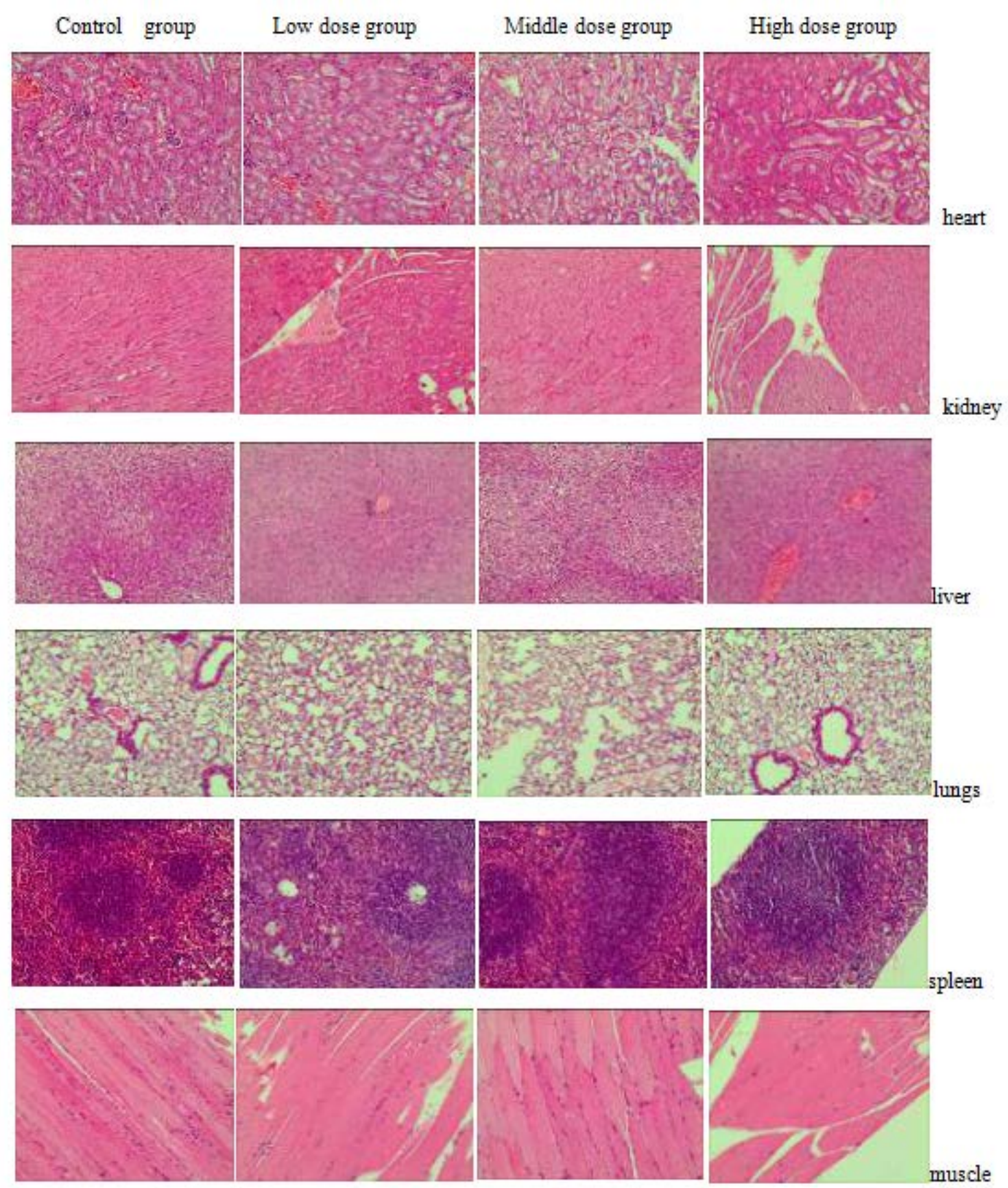

Figure 4. Pictures of pathological section for each group of main organs

\subsection{The Animal Reproductive Toxicity of HAP/Arg}

\subsubsection{The Effect of HAP/Arg on Kunming Mice}

Table 5 showed the female conception rate results in each group after male and female mice were put in the same cage. No death was observed in each dose group before mating or during the mating period. And no obvious abnormality was found in the anatomy of heart, spleen, lung, liver, kidney and muscle. Besides, no significant differences were noticed in the rate of mating of male rats and the rate of pregnancy after mating between each dose group and the control group. 
Table 5. The result of fecundation rate of female little mice.

\begin{tabular}{lcccc}
\hline \multicolumn{1}{c}{ Groups } & Duration of reproduction (day) & Number of litter size & Rate of fecundation (\%) & P value \\
\hline Control group & 5 & 13 & 65 & \\
Low dose group & 7 & 13 & 65 & $>0.05$ \\
Middle dose group & 7 & 12 & 60 & $>0.05$ \\
High dose group & 5 & 13 & 65 & $>0.05$ \\
\hline
\end{tabular}

Table 6 showed the comparison of testis weight and epididymis weight of male mice. As can be seen from the table, the average weight of testis and epididymis in the administration groups were different from those in the control group. However, no significant difference was found in organ coefficient $(\mathrm{P}>0.05)$, and no dose response relationship was showed among the three experimental groups of different concentrations of $\mathrm{HAP} / \mathrm{Arg}$.

Table 6. Comparison of testicle and epididymis weight between tests and control groups.

\begin{tabular}{lcccc}
\hline \multicolumn{1}{c}{ Groups } & Testicle and Epididymis weight $(\mathrm{g})$ & Number of litter size & Organ Coefficient & P value \\
\hline Control group & $1.2 \pm 0.03$ & 10 & $21.53 \pm 0.02$ & \\
Low dose group & $0.9 \pm 0.02$ & 10 & $16.16 \pm 0.02$ & $>0.05$ \\
Middle dose group & $0.9 \pm 0.01$ & 10 & $17.95 \pm 0.03$ & $>0.05$ \\
High dose group & $0.9 \pm 0.02$ & 10 & $16.98 \pm 0.01$ & $>0.05$ \\
\hline
\end{tabular}

\subsubsection{The Effect of HAP/Arg on the Fetus}

No morphological abnormalities were found in the fetal pups of Kunming mice which were randomly selected from the $0.09 \mathrm{mg} / \mathrm{kg} \cdot \mathrm{d}$ group, $4.5 \mathrm{mg} / \mathrm{kg} \cdot \mathrm{d}$ group, and $225 \mathrm{mg} / \mathrm{kg} \cdot \mathrm{d}$ group. No obvious abnormality was observed in the visceral soft tissues of the fetus, and the number of nest or incidence rate had no significant difference between each experimental group and the control group $(\mathrm{P}>0.05)$. The skeletal examination of fetal failed to find any ossification phenomenon in the first center of sternebra and pubic bone. Meanwhile, there were no obvious cartilage abnormalities in each dose group.

\section{Conclusions}

HAP/Arg could be used for the detection of biological safety. HAP/Arg suspension of each dose did not affect normal growth and cell membrane structure of normal vascular endothelial cells (HAEC) and human tumor cells (Hela cells) under different duration. In addition, the effect of HAP/Arg on cell membrane structure was not significant.

During the experimental period, no obvious abnormalities in the activities, weight, hair color, stool, urine, feed intake and breath of mice were found to be related to the reaction of HAP/Arg, and this illustrated that HAP/Arg prepared by hydrothermal synthesis method had no acute toxicity, but whether there was a chronic toxic effect remained to be further studied.

When the effect of HAP/Arg on five kinds of serum biochemical indexes of Kunming mice was analyzed, it was clear that the serum alanine amino transfer enzyme (ALT) of mice in the high dose group of HAP/Arg was obviously different from the control group, this result might be associated with the transportation of a large number of particles to the liver cells by macrophages of the reticular endothelial system (RES). There was no significant difference between other dose groups and control group on serum biochemical indexes, such as AST, TP, BUN and CREA, indicating that HAP/Arg in each dose group were less harmful to kidney and liver. The pathological sections of heart, spleen, lung, liver, kidney and muscle were observed by inverted fluorescence microscope and no inflammation or damage of the structure of cells in different tissues were found.

HAP/Arg had no obvious reproductive toxicity to animals. Meanwhile, there were no significant differences in the rate of mating of male mice and the rate of pregnancy after mating between each dose group and the control group. And no significant abnormality in the appearance and the visceral soft tissues of the fetus were noticed. In addition, the skeletal examination of fetal failed to find any obvious cartilage abnormalities and ossification phenomenon in the first center of sternebra and pubic bone. 
Conflict of interest. The authors declare that they have no competing interests.

Acknowledgements. This study was supported by the Key Research and Development Project of Hunan Province (2016JC2064), Specialized Research Fund for the Doctoral Program of Higher Education of China (20130162120094), and Open Project of State Key Laboratory of Powder Metallurgy of Central South University.

\section{References}

1. S.H. Zhu, B.Y. Huang, K.C. Zhou, S.P. Huang, F. Liu, and Y.M. Li, "Hydroxyapatite Nanoparticles as a Novel Gene Carrier,"Journal of Nanoparticle Research, vol. 22,no. 5, pp.980-984,2005.

2. T.N. Do, W.H. Lee, C.Y. Loo, A.V. Zavgorodniy, and R. Rohanizadeh, "Hydroxyapatite nanoparticles as vectors for gene delivery,"Therapeutic Delivery, vol. 3,no. 5, pp.623-632,2012.

3. G. Zuo, Y. Wan, and Y. Zhang, "Preparation and characterization of a novel laminated magnetic hydroxyapatite for application on gene delivery,"Materials Letters, vol. 68, pp.225-227,2012.

4. H. Sun, M. Jiang, and S.H. Zhu, "In vitro and in vivo studies on hydroxyapatite nanoparticles as a novel vector for inner ear gene therapy,"Zhonghua Er Bi Yan Hou Tou Jing Wai Ke Za Zhi, vol. 43,no. 1, pp.51-57,2008.

5. Y.Z. Zhao, S.H. Zhu, J. Tan, Y.Y. Huang, Zh.Y. Li, and K.C. Zhou, "Arginine modification and gene binding of hydroxyapatite nanoparticles,"Zhongguo Youse Jinshu Xuebao/chinese Journal of Nonferrous Metals,vol.20,no.6, pp.1203-1208,2010.

6. G.H. Wang, Y.Z. Zhao, J.Tan, S.H. Zhu, and K.C. Zhou, "Arginine functionalized hydroxyapatite nanoparticles and its bioactivity for gene delivery,"Transactions of Nonferrous Metals Society of China,vol.25,no.2, pp.490-496,2015.

7. Z. Siprashvil, F.A. Scholl, S.F. Oliver, A. Adams, C.H. Contag, P.A. Wender, and P.A. Khavari,"Gene transfer via reversible plasmid condensation with cysteine-flanked, internally spaced arginine-rich peptides,"Human Gene Therapy, vol.14, no.13, pp.1225-1233,2003.

8. S. Futaki, W. Ohashi, T. Suzuki, M. Niwa, S. Tanaka, K. Ueda, H. Harashima, and Y. Sugiura, "Stearylated ariginine-rich peptides: A new class of transfection systems,"Bioconjugate Chemistry,vol.12, no.6, pp.1005-1011,2001.

9. A.D.Maynard, "Nanotechnology:assessing the risk,"Nano Today, vol.1, no.2, pp.22-33,2006.

10. W. Hannah, and P.B. Thompson,"Nanotechnology,risk and the environment:a review,"Journal of Environmental Monitoring Jem,vol.10, no.3, pp.291-300, 2008.

11. A. Maynard, and D. Rejeski, "Too small to overlook,"Nature, vol.460, no.7252, pp.174-174, 2009.

12. A.M. Fan, and G. Alexeeff, "Nanotechnology and nanomaterials: toxicology, risk assessment, and regulations,"Journal of Nanoscience and Nanotechnology, vol.10, no.12, pp.8646-8657, 2010.

13. E.M. Forsberg, "Standardisation in the field of nanotechnology: some issues of legitimacy,"Science and Engineering Ethics,vol.18, no.4, pp.719-739,2012.

14. A. Besinis,T. De-Peralta,C.J.Tredwin, and R.D.Handy, "Review of nanomaterials in dentistry: interactions with the oral microenvironment, clinical applications, hazards, and benefits,"ACS Nano, vol.9, no.3, pp.2255-2289,2015.

15. R.Z. Legeros, "Properties of osteoconductive biomaterials: calciumphosphates,"Clinical Orthopaedics and Related Research,vol.395, no.395, pp.81-98,2002.

16. H.Aoki, and T.Kutsuno, "An in vivo study on the reaction of hydroxyapatite-sol injected into blood," Journal of Materials Science:Materials in Medicine,vol.11, no.2, pp.67-72,2000.

17. J.L. Tang, and T.F. Xi, "Research status of the biological safety of nano-hydroxyapatite," Journal of Clinical Rehabilitative Tissue Engineering Research,vol.11, no.5, pp.936-943,2007.

18. G. Oberdorster, Z. Sharp, V. Atudorei, A. Elder, R. Gelein, A. Lunts, W. Kreyling, and C. Cox, "Extrapulmonary translocation of ultrafine carbon particles following whole-body inhalation exposure of rats,"Journal of Toxicology and Environmental Health Part A,vol.65, no.20, pp.1531-1543,2002.

19. X. Wu, Y. Tan,H. Mao, and M. Zhang, "Toxic effects of iron oxide nanoparticles on human umbilical vein endothelial cells,"International Journal of Nanomedicine,vol.5,no.1,pp.385-399,2010.

20. Y.Sh. Dong, "The establishment and practice of a standard toxicopathological platform in drug safety evaluation,"Beijing: The Chinese people's Liberation Army Military Medical Science Academy,2012. 
21. D.R. Joseph, L. Demin, and W.B. Lin, "Nanoscale metal-organic frameworks for biomedical imaging and drug delivery,"Acc.chem.res, vol.44,no.10,pp.957-968,2011.

22. J.N. Liu, X.L. Wei, H. Jiang, and W.Zh. Zhong,"Preparation and Transfer Efficiency of Modified PAMAM Dendrimer Gene Delivery,"Journal of Huazhong Agricultural University,vol.29,no.3,pp.333-334,2010. 